\title{
INTEGRACIÓN SOCIAL Y DERECHO A LA EDUCACIÓN: A PROPÓSITO DE LA SENTENCIA DE 10 DE ENERO DE 2017, DEL TRIBUNAL EUROPEO DE DERECHOS HUMANOS
}

Social integration and the right to education:

With regard to the judgment of 10 January 2017, of the European Court of Human Rights

\author{
ANA VALERO HEREDIA \\ Universidad de Castilla-La Mancha \\ Anamaria.valero@uclm.es
}

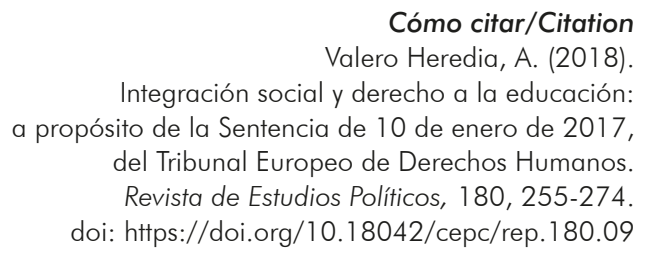

\section{Resumen}

Las objeciones de conciencia por parte de los padres a que sus hijos reciban formación en determinadas materias del currículo educativo oficial es cada vez más habitual en sociedades plurales como las nuestras. El derecho al que se apela para justificar tales objeciones es el derecho de los padres a orientar la educación de sus hijos conforme a sus convicciones. En el presente estudio acudimos al análisis de la reciente Sentencia del Tribunal Europeo de Derechos Humanos de 10 de enero de 2017, para estudiar qué derechos entran en conflicto en los supuestos en que los padres no quieren que sus hijos acudan a clases de natación, como en el presente caso, o de educación sexual, religión o darwinismo. Y para ello nos servimos del análisis otras sentencias de la Corte de Estrasburgo, del Tribunal Supremo norteamericano y del Tribunal Constitucional español.

\section{Palabras clave}

Objeción de conciencia; derecho a la educación; derechos educativos paternos; libertad religiosa; adoctrinamiento; ideario educativo. 


\begin{abstract}
Conscientious objections by parents that their children receive training in certain subjects within the official educational curriculum are increasingly common in plural societies. Such objections are justified by the parents' right to orient the education of their children according to their convictions. In the present study we analyse the recent judgment of the European Court of Human Rights of January 10th, 2017, to study what rights are in conflict in cases where parents do not want their children to attend swimming classes, sex education, religion, or be instructed about Darwinism. With this in mind, we analyze other relevant judgments of the Court of Strasbourg, the US Supreme Court and the Spanish Constitutional Court.
\end{abstract}

\title{
Keywords
}

Objection of conscience; right to education; paternal educational rights; religious freedom; indoctrination; educational ideology. 


\section{SUMARIO}

I. INTRODUCCIÓN. II. LOS DERECHOS EDUCATIVOS PATERNOS: DERECHOS DE LIBERTAD Y NO DE PRESTACIÓN. III. EL "ADOCTRINAMIENTO» COMO LÍMITE INFRANQUEABLE PARA EL ESTADO EN LA ORGANIZACIÓN Y TRANSMISIÓN DEL CURRÍCULO EDUCATIVO: 1. La objeción a la educación sexual. 2. La objeción a la educación "sobre» la religión. 3. La objeción a la educación en la teoría del evolucionismo o darwinismo. 4. La objeción a la educación física y a la natación. IV. LA EDUCACIÓN «INTEGRAL» DE LOS MENORES. BIBLIOGRAFIA.

\section{INTRODUCCIÓN}

En su reciente Sentencia de 10 de enero de 2017, el Tribunal Europeo de Derechos Humanos aborda la cuestión relativa al derecho de los padres a objetar en conciencia a que sus hijos reciban formación en determinadas materias obligatorias del currículo educativo. No es la primera vez que el juez de Estrasburgo se encuentra con un supuesto de este tipo, donde deber dilucidar si cursar todas y cada una de las materias integradas en el programa educativo oficial se hace imprescindible para la educación «integral» de los menores y en qué medida este derecho debe o no prevalecer sobre las convicciones religiosas, ideológicas o filosóficas de sus progenitores.

La sentencia objeto de estudio rechaza la demanda de unos padres contra la Confederación suiza, confirmando con ello la Sentencia del Tribunal Federal de 7 de marzo de 2012 que apelaba al valor que para la «integración social» del alumnado tiene la asistencia a todos los cursos previstos en la programación educativa, incluida la natación, con independencia de sus orígenes, culturas y religiones, siendo este un interés público prevalente sobre las convicciones paternas.

Sin perjuicio de ir desgranando con más detalle en los próximos epígrafes los argumentos aducidos por los progenitores, fervientes practicantes de la religión musulmana, cabe anticipar que los mismos se basaban sucintamente en la negativa a que sus hijas asistiesen al curso de natación mixta pues, aunque el Corán no exige que el cuerpo femenino sea cubierto sino a partir de la pubertad, sus creencias les exigían prepararlas para ello y, en tanto que titulares de la autoridad paterna, los progenitores denunciaban una violación de sus derechos.

A la vista de lo expuesto puede afirmarse que la cuestión central que resuelve la presente sentencia atiende a los límites que son aplicables tanto a 
los derechos educativos paternos como a la libertad religiosa de estos cuando el derecho de los menores a recibir una educación que coadyuve al libre desarrollo de su personalidad está en juego.

En tal sentido, en los próximos epígrafes se llevará a cabo un análisis de los derechos fundamentales en conflicto. Con dicho fin se procederá al estudio del régimen jurídico del derecho de los padres a orientar la educación de sus hijos y los criterios que deben regir su correcta conciliación con el derecho de los niños a recibir una educación integral que contribuya al pleno desarrollo de su personalidad. Tratando de determinar, acto seguido, si este último derecho requiere de algo más que de una educación en contenidos y conocimientos curriculares.

\section{LOS DERECHOS EDUCATIVOS PATERNOS: DERECHOS DE LIBERTAD Y NO DE PRESTACIÓN}

Como el resto de los derechos que componen la libertad de enseñanza, el derecho de los padres a educar a sus hijos conforme a sus propias convicciones y el derecho a elegir para ellos una concreta formación religiosa y moral se configuran como una proyección de los derechos de libertad ideológica, religiosa y filosófica de aquellos. En palabras de la Corte Europea: «El derecho de los padres a decidir el tipo de educación que habrá de darse a sus hijos está íntimamente ligado a la libertad de pensamiento, conciencia y religión —artículo 9 del Convenio— ${ }^{1}$.

La Corte Europea de Estrasburgo ha apreciado en su jurisprudencia que el pluralismo de ideas y creencias — concretado en la libertad de enseńanzaes consustancial, junto con los principios de tolerancia y espíritu de apertura, al modelo de sociedad democrática enunciado en el Convenio, que trata de garantizar lo que la doctrina ha denominado «el derecho a la educación en libertad $»^{2}$.

Además, y aunque por lo que respecta al presente caso Suiza no ha ratificado el Protocolo Adicional Primero al Convenio para la Protección de los

1 SSTEDH de 7 de diciembre de 1976, en el caso Kjeldsen, Busk Madsen y Pedersen c. Dinamarca, de 25 de febrero de 1982, en el caso Campbell y Cosans c. Reino Unido y de 18 de diciembre de 1996, en el caso Valsamis c. Grecia.

2 SSTEDH de 22 de octubre de 1981, en el caso Dudgeon c. Reino Unido; de 19 de diciembre de 1994, en el caso Verinigung Demokratischer Soldaten Österreichs und Gubi c. Austria; de 27 de septiembre de 1999, en el caso Lustig-Prean y Beckett c. Reino Unido. 
Derechos Humanos y las Libertades Fundamentales del Consejo de Europa, su art. 2 reconoce, tras promulgar la universalidad del derecho a la instrucción, que: «El Estado, en el ejercicio de las funciones asumidas en el campo de la educación y de la enseñanza, respetará el derecho de los padres a adoptar la educación que consideren más adecuada para el menor, de conformidad con sus convicciones religiosas y filosóficas».

Pues bien, el deber que la posición jurídica de libertad de los padres con respecto a la educación de sus hijos comporta para los poderes públicos — como sujetos pasivos de tal derecho-, es un deber de índole "negativa», de protección y respeto, pero nunca de prestación. En correlación con la naturaleza jurídica del derecho fundamental del que es proyección o manifestación jurídica - la libertad de pensamiento, conciencia y religión-, el derecho reconocido en el art. 2 del Protocolo Adicional Primero, al igual que el resto de derechos que integran la libertad de enseñanza y en contraposición con el carácter prestacional del derecho a la educación, debe ser calificado como un derecho de libertad o derecho de autonomía frente a los poderes públicos.

Se trata de un derecho de libertad que no atribuye a sus titulares más que la facultad de que se respete un ámbito propio de autonomía y se garantice una correlativa esfera de inmunidad de coacción. En este sentido, la obligación principal asumida por los poderes públicos es claramente una obligación de abstención y de no interferencia.

En virtud de dicho deber de abstención y de no interferencia, los poderes públicos quedan obligados jurídicamente a «respetar» las convicciones ideológicas, religiosas o filosóficas de los progenitores en el contenido de las enseñanzas transmitidas a los hijos y en el método a través del cual las mismas se imparten en el seno de la escuela, lo que en ningún caso viene a significar que el Estado se halle compelido a gestionar en el ámbito de la enseńanza una plena acomodación de aquellas. De acuerdo con ello, puede afirmarse que el derecho educativo paterno es un derecho de libertad o derecho reaccional, nunca prestacional, cuyo objeto cristaliza en la prohibición de una determinada conducta estatal de carácter «adoctrinador». En este sentido, la Sentencia de 10 de enero de 2017 seńala que:

La palabra respeto a la que hace referencia el artículo 2 del Protocolo I implica que los Estados tienen un amplio margen de apreciación para determinar, en base a las necesidades y recursos de la comunidad y de los individuos, las medidas para garantizar el cumplimiento de la Convención. Por lo que esta disposición no puede interpretarse como que permite a los padres a exigir al Estado que organice una educación determinada. 
La responsabilidad de respetar las convicciones religiosas, ideológicas y filosóficas de los progenitores recae sobre el poder estatal en su condición de ejerciente de las competencias a él asignadas en materia de regulación del sistema educativo. Dicha responsabilidad, que posee un carácter amplio en la medida en que convierte al Estado en garante de la actuación de todos sus «órganos, agentes y funcionarios» —incluido el comportamiento singular de las autoridades educativas y centros públicos de enseñanza-, extiende su objeto material a todo el sistema de enseñanza, tanto público como privado, lo que supone que el reconocimiento de las escuelas privadas no exime al Estado de su obligación de respetar las convicciones paternas en el marco de la escuela pública.

El Tribunal Europeo ha señalado asimismo que en el seno del sistema público de enseñanza, dicha obligación no se circunscribe al modo en cómo se imparte la enseñanza religiosa, sino que se extiende a todo el programa educativo y al modo en cómo se imparten cada una de materias integrantes del currículo. Y, con la clara voluntad de ahondar en la interpretación expansiva de las garantías ofrecidas por el art. 2 del Protocolo I, el mismo ha llegado a sostener que el límite erigido frente al Estado no solo comprende los contenidos estrictos de la enseñanza, sino también otros aspectos de la educación como el modelo disciplinario ${ }^{3}$.

De todo lo expuesto se obtiene una conclusión en la que el Tribunal Europeo de Derechos Humanos ha incidido en sus distintos pronunciamientos: que el preceptivo respeto de las convicciones paternas queda satisfecho siempre y cuando los poderes públicos no persigan un fin de «adoctrinamiento" de los menores en contra de la voluntad de sus padres o sin el consentimiento de estos en el ejercicio de sus competencias en materia educativa, impidiéndose con ello formaciones ideológicas imperativamente predispuestas desde el Estado.

\section{EL «ADOCTRINAMIENTO» COMO LÍMITE INFRANQUEABLE PARA EL ESTADO EN LA ORGANIZACIÓN Y TRANSMISIÓN DEL CURRÍCULO EDUCATIVO}

La realización material del derecho a la educación en el marco de un Estado social requiere la articulación de un servicio público y una programación general de la enseñanza. En el desempeño de sus competencias en esta materia, el Estado posee la plena capacidad para definir los contenidos

3 Casos Campbell y Cosans c. Reino Unido y Valsamis c. Grecia. 
curriculares de la enseñanza básica obligatoria o, en palabras de la Corte Europea de Estrasburgo, fijar los planes de estudio, disponiendo de un amplio margen de apreciación basado en razones de oportunidad o conveniencia. El Estado se halla legitimado, por tanto, para ordenar el sistema educativo estableciendo una regulación general y uniforme aplicable a cualquier tipo de enseñanza. En esta medida, corresponde al legislador no solo la decisión de qué enseñanzas son las que en cada momento histórico coadyuvan la consecución de los fines educativos constitucionalmente previstos sino también la fijación de los principios pedagógicos adecuados para alcanzar dichos fines.

La escolarización obligatoria comprende el deber de recibir la enseńanza diseñada por los poderes públicos como básica y el de participar en las actividades escolares declaradas como obligatorias; sin embargo, el contenido de algunas de las materias o enseñanzas curriculares puede entrar en contradicción con el derecho de los padres a educar a sus hijos conforme a sus convicciones. En sociedades plurales como las actuales, los supuestos de objeción de conciencia en relación con distintas materias integradas en el sistema educativo reglado se plantean cada vez de manera más habitual. Así, a la objeción de conciencia a la educación sexual, que fue planteada ya en los años setenta ante la Corte de Estrasburgo, se suma un amplio abanico de objeciones cuya actualidad se halla ligada a la profunda transformación de las sociedades occidentales cada vez más acostumbradas a una mayor heterogeneidad de credos, costumbres y culturas.

Entre dichas objeciones de nuevo cuño destacan las planteadas por algunos padres de religión musulmana a la educación física o a la natación, como en el caso examinado en la sentencia objeto de estudio, a la asignatura de ciencias naturales o a la de música, o la negativa de ciertos padres con convicciones de raíz cristiana en Estados Unidos a que sus hijos adquieran conocimientos sobre la teoría evolucionista o el darwinismo.

Desde una perspectiva constitucional, la cuestión capital trazada por este tipo de objeciones reside, como se señalaba al inicio del presente estudio, en el conflicto que plantean entre el derecho educativo paterno - pues la reclamada exención halla sustento en los dictados de las convicciones de los progenitores - y el derecho del menor a recibir una formación integral que contribuya al libre desarrollo de su personalidad (Aláez Corral, 2003; Valero Heredia, 2009). Y los criterios para su resolución fueron diseñados, años atrás, por el Tribunal Europeo de Derechos Humanos en la sentencia promulgada en el caso Kjeldsen, Bush Madsen y Pedersen c. Dinamarca, de 7 de diciembre de 1976, criterios después reiterados en un pronunciamiento de 29 de junio de 2007, en el caso Folgero c. Noruega y que hoy se vuelven a afianzar en la reciente Sentencia de 10 de enero de 2017 (Aláez Corral, 2008; Barrero Ortega, 2009). 
A través de estas sentencias, el juez de Estrasburgo ha establecido una importante doctrina cuyos parámetros esenciales resultan enormemente útiles para el enjuiciamiento de este tipo de supuestos de objeción parcial al sistema homologado de enseñanza. Dichos parámetros, que serán desarrollados en los próximos epígrafes, se resumen como sigue: el Estado, en el ejercicio de sus competencias en materia educativa, no se encuentra constreńido a acomodar plenamente las convicciones paternas, hallándose únicamente impedido para perseguir un fin de adoctrinamiento.

A continuación veremos algunos ejemplos de objeciones paternas a materias concretas que han ocasionado pronunciamientos del Tribunal Europeo de Derechos Humanos, pues en ellos se anticipa la doctrina que este emplea en la sentencia objeto del presente estudio. Asimismo, analizaremos los pronunciamientos del Tribunal Supremo norteamericano sobre la objeción a la enseñanza del darwinismo en la escuela pública y a la enseñanza de la religión, pues su doctrina posee, indudablemente, criterios de interpretación similares a los empleados por la Corte Europea.

\section{LA OBJECIÓN A LA EDUCACIÓN SEXUAL}

Por lo que respecta al análisis de la sentencia del año 76 del Tribunal Europeo, debemos señalar que Kjeldsen, Bush Madsen y Pedersen eran tres familias cristianas con hijos de corta edad que impugnaron una reforma educativa introducida por la ley danesa de 27 de mayo de 1970, en virtud de la cual se imponía la enseńanza sexual integrada y obligatoria en las escuelas públicas durante la educación primaria. El carácter obligatorio de la materia, que al ser «integrada» no se configuraba como una asignatura independiente, sino que era introducida con carácter transversal en el resto de materias escolares, implicaba que la ley no previese la posibilidad de exención para los alumnos por causa de las convicciones religiosas o morales de los padres, lo que condujo a los demandantes a estimar que la integración de dicha materia en el currículo educativo de las escuelas públicas violaba sus convicciones de padres cristianos, vulnerando así el derecho reconocido en el art. 2 del Protocolo Adicional Primero. Junto a esta disposición, los demandantes consideraron asimismo vulnerado el art. 9 del Convenio, relativo a la libertad de pensamiento, de conciencia y de religión, y el art. 14, que consagra el principio de igualdad.

El juez de Estrasburgo señaló que el Estado posee la plena competencia para fijar los planes de estudio, competencia que la Corte no está legitimada para enjuiciar, y sostuvo que el art. 2 del Primer Protocolo no impide al Estado que, en el establecimiento de los contenidos integrados en dichos planes de estudio, pueda incluir materias que tengan por finalidad difundir 
informaciones o conocimientos dotados directa o indirectamente de una índole ideológica o religiosa. Asimismo, afirmó que dicho precepto «no autoriza, ni siquiera a los padres, a oponerse a la integración de tal enseñanza o educación en el programa escolar, ya que si tal fuera el caso, cualquier enseńanza correría el riesgo de mostrarse impracticable [...]». Por el contrario, lo que la segunda frase del art. 2 efectivamente exige es que «[...] el Estado, cuando cumpla las funciones por él asumidas en materia de educación y enseñanza, vigile que las informaciones o conocimientos que figuran en el programa sean difundidos de manera objetiva, crítica y pluralista", impidiéndose, a través de dicho límite infranqueable, que el Estado persiga una finalidad de adoctrinamiento de los alumnos que menoscabe las convicciones religiosas y filosóficas de los progenitores.

Sobre los fundamentos de esta importante doctrina, el Tribunal estimó que introduciendo la enseñanza sexual en el currículo educativo no se vulneraba el derecho reconocido a los progenitores en el art. 2 del Protocolo Adicional Primero en la medida en que su organización, destinada a la mera transmisión parcial de conocimientos, respetaba las exigencias de «objetividad, neutralidad y pluralismo» establecidas como requisitos imprescindibles para evitar una actitud adoctrinadora por parte del Estado. De este modo, y en ello radica la piedra angular de la sentencia, no tenía cabida la previsión de exenciones de los menores sobre la base de las convicciones religiosas, ideológicas o filosóficas de sus progenitores, habida cuenta que, con la promulgación de la ley, se perseguía la satisfacción de un fin legítimo por razones de interés público.

Quizás lo más significativo que puede deducirse de las palabras del Tribunal Europeo a los efectos que ahora interesan radica en que, si bien resulta categórica la prohibición que recae sobre los poderes públicos de llevar a cabo cualquier labor de adoctrinamiento en el desempeño de sus funciones educativas - la cual engarza con el principio de neutralidad ideológica y religiosa de los poderes públicos-, dicha prohibición no impide que, en aras a favorecer la «educación integral» de los menores, aquellos incluyan en la organización del sistema educativo materias que - sin incurrir en un «proselitismo intempestivo" - contribuyan a ello, siempre que dichas informaciones o conocimientos sean difundidos de manera objetiva, crítica y razonable. De modo que, aun cuando el currículo de la materia en cuestión pueda llevar a los educandos a cuestionarse o contrastar las informaciones recibidas en casa - piénsese en este caso en cómo el tratamiento en la escuela de cuestiones relativas a la anticoncepción en el ámbito de la formación sexual de los menores podría influir en la conformación de juicios de valor diversos a los dogmas sobre los que se sustentan las convicciones cristianas de los padres-, el derecho de los nińos a recibir una educación integral 
asentada sobre los principios de libertad, pluralismo y espíritu crítico habilita a los poderes públicos a incluirla en el currículo educativo. De este modo, el límite infranqueable que impide el intento adoctrinador por parte del Estado queda sorteado mediante la garantía del tratamiento neutral de la materia (Martí Sánchez, 2007).

\section{LA OBJECIÓN A LA EDUCACIÓN «SOBRE» LA RELIGIÓN}

La doctrina mantenida por la Corte de Estrasburgo en el caso Kjeldsen fue la empleada años más tarde por la Comisión Europea de Derechos Humanos para abordar otro tipo de objeciones, aquellas que reclaman la exclusión de los hijos del deber de cursar la enseńanza sobre la religión en la escuela. En su decisión sobre el caso Lena y Anna Angelini c. Suecia , la Comisión declaró inadmisible la demanda de una madre de convicciones ateas que estimaba vulnerado el art. 2 del Protocolo Adicional Primero al haberle sido denegado el derecho a que su hija fuera eximida de las clases de instrucción religiosa en un colegio público sueco. Tras comprobar que se trataba de una enseñanza «sobre» la religión y no una instrucción «en» una religión concreta, la Comisión rechazó que se hubiere producido una vulneración del derecho educativo paterno. Pues en la medida en que la organización de la materia respondía a los criterios de "neutralidad, objetividad y pluralismo», quedaba ahuyentado todo riesgo de adoctrinamiento por parte del Estado. Ello condujo a la Comisión a afirmar la legitimidad del fin que el Gobierno sueco perseguía con la introducción de tal enseñanza en el currículo educativo: dotar a los alumnos de ciertos conocimientos esenciales para la formación cultural de la juventud en un país occidental.

Años más tarde, el Tribunal Europeo de Derechos Humanos ratificó dicha doctrina en su Sentencia de 29 de junio de 2007, en el caso Fogero c. Noruega. En ella el juez de Estrasburgo condenó al Estado noruego por incluir en el currículo educativo oficial con carácter obligatorio una materia llamada Cristianismo, Religión y Filosofía. La Corte sostuvo que la citada asignatura, aun incluyendo fines perfectamente acordes con las exigencias del Convenio, como «enseñar conjuntamente el cristianismo y otras religiones y filosofías con el fin de convertir a la escuela en un lugar de encuentro de las diferentes convicciones religiosas y filosóficas y donde todos los alumnos puedan conocer los pensamientos y tradiciones de sus compañeros», vulneraba el art. 2 del Protocolo Adicional Primero. Y ello porque el Estado noruego no había adoptado todos los medios necesarios para garantizar que las informaciones y

4 Decisión de la Comisión 10491/83. 
conocimientos incluidos en el programa de la asignatura fueran difundidos de manera "objetiva, neutral y pluralista».

De esta jurisprudencia de los órganos de Estrasburgo se extrae que el Estado se halla legitimado para introducir en los planes de estudio una enseñanza no catequética sobre la religión o sobre cualesquiera otros fenómenos de carácter ideológico o religioso siempre y cuando el tratamiento de la materia se realice desde criterios de objetividad, neutralidad y pluralismo.

\section{LA OBJECIÓN A LA EDUCACIÓN EN LA TEORÍA DEL EVOLUCIONISMO O DARWINISMO}

En Estados Unidos la Corte Suprema ha debido pronunciarse en relación a la demanda de diversos grupos cristianos que, durante ańos y basándose en una interpretación literal de la Biblia, han tratado de expulsar del currículo educativo de la escuela pública la enseñanza de la teoría evolutiva o han pretendido que la misma fuese expuesta a los alumnos como una teoría más e impartida en igualdad de condiciones a la teoría del creacionismo.

Puede anticiparse que, en esencia, la Corte Constitucional estadounidense ha tratado el "creacionismo» como una materia incardinada bajo la categoría de «enseñanza de la religión» y, como tal, la ha sometido a la doctrina del separatismo. Así, en las sentencias promulgadas en los casos Epperson v. Arkansas $(1968)^{5}$ y Edwards v. Aguillard (1987) ${ }^{6}$, la Corte invalidó sendas leyes que prohibían la enseñanza de la evolución o que promovían la enseñanza del creacionismo en los programas educativos de la escuela pública, afirmando que las mismas fueron adoptadas para promover y fomentar una concepción religiosa del origen del ser humano y que, en esencia, respondían al propósito de avanzar la religión frente a la irreligión confiriendo a la primera determinados beneficios que resultaban deliberadamente discriminatorios y constitucionalmente inadmisibles.

Concretamente, en el caso Epperson, la Corte Constitucional declaró inválida una ley del Estado de Arkansas del año 29 que prohibía que en las instituciones educativas financiadas por el Estado - incluidas las universidades, colegios y escuelas públicas - se instruyese en la teoría de que el ser humano desciende de otras especies animales anteriores. El juez Fortas, en nombre de la mayoría, afirmó que la Primera Enmienda no permite que el Estado pueda adaptar la enseñanza a los principios o prohibiciones de ningún dogma religioso. Concretamente, dispuso:

393 U.S. 97 (1968).

482 U.S. 578 (1987). 
La ley cuya constitucionalidad se discute selecciona del cuerpo de conocimiento un particular segmento que la misma prohíbe por la sola razón de que se encuentra en profundo conflicto con la una particular doctrina religiosa, concretamente, con una particular interpretación del Libro del Génesis por parte de un particular grupo religioso.

En consecuencia, afirmó que la ley carecía de un "propósito secular» sobre la base de dos motivos: a) "Ninguna sugerencia había sido hecha en orden a considerar que la ley de Arkansas podía estar justificada sobre la base de consideraciones de política estatal más allá del punto de vista religioso de algunos de sus ciudadanos»; y b) «Una convicción religiosa extrema fue y es la razón de la existencia de la ley».

A través de un anticipo de lo que sería la doctrina después perfeccionada en el llamado Lemon Test, la Corte dispuso que la norma enjuiciada violaba la neutralidad del Estado en materia religiosa, afirmando que empleaba medios ilegítimos - como la criminalización de la enseñanza de una doctrina científica - en orden a satisfacer un fin constitucionalmente inadecuado - el establecimiento de la religión en el currículo de la escuela pública-.

Se observa cómo, en el caso Epperson, la Corte aplica al ámbito de la escuela pública la importante doctrina de la neutralidad del Estado en materia religiosa afirmando que:

El gobierno debe ser neutral en los asuntos relacionados con la teoría, doctrina y práctica religiosa. No debe ser hostil hacia ninguna religión o hacia doctrinas o filosofías no religiosas; asimismo, no debe ayudar, fomentar o promover una religión o una teoría religiosa contra otra o contra su militante oposición. La Primera Enmienda impone la neutralidad gubernamental entre las distintas religiones y entre la religión y la no religión, también en la escuela pública.

Con esta jurisprudencia la Corte no está afirmando que cualquier crítica que se realice contra el llamado "darwinismo o teoría de la evolución» deba ser considerada, en todo caso, inconstitucional. Antes bien, lo que la alta instancia norteamericana quiere decir es que prohibir la discusión académica acerca de la teoría darwiniana en el seno de la escuela pública — discusión, por otra parte, necesaria para el avance del conocimiento humano- contradice el mandato de la Primera Enmienda constitucional en tanto que tal prohibición produce como efecto el avance o promoción de determinadas creencias religiosas. El Estado y sus instituciones no pueden voluntariamente favorecer o perjudicar a determinadas convicciones religiosas o antirreligiosas (Polo Sabau, 2003). 
Dos décadas más tarde, la Corte hubo de afrontar una variante más compleja del problema de la enseñanza de la teoría de la evolución en la escuela pública. En el caso Edwards v. Aguillard (1987) se dirimía la constitucionalidad de una norma del Estado de Lousiana que no impedía categóricamente la enseñanza de dicha teoría en las escuelas, sino que disponía que aquellas que optasen por impartir a sus alumnos las líneas básicas del evolucionismo debían asimismo incorporar a su programa educativo la enseñanza de la teoría creacionista — "Ballanced Treatment for Creation-Science and Evolution-Science in Public School Instruction»-. Otorgar un tratamiento ecuánime a ambas teorías en el seno de los programas escolares respondía, de acuerdo con los promotores de la ley, a la voluntad de proteger el derecho de los menores a recibir una instrucción plural respecto a la cuestión del origen del hombre.

La Corte Suprema recurrió en este caso a la doctrina del Lemon Test, cuyas directrices ya habían sido formuladas en el importante caso Lemon v. Kurtzman $(1971)^{7}$, para dictar, atendiendo al primero de sus tres requisitos, que la norma enjuiciada carecía de un propósito estrictamente secular. La voluntad de sus promulgadores no era ampliar los conocimientos que sobre el origen del hombre podían adquirir los estudiantes, sino sujetar la enseñanza de todo lo relativo a este asunto a la visión de una confesión religiosa concreta. Dicha sujeción se hacía evidente en la norma al condicionar la enseñanza de una teoría —el darwinismo - a la enseñanza inexorable de la otra —el creacionismo--, lo que llevó a la Corte a estimar que aquella no tenía como principal propósito impulsar una «instrucción objetiva» en materia religiosa, sino el establecimiento inconstitucional de la religión. En palabras concretas del juez Brennan: «El preeminente objetivo de la ley de Lousiana era claramente el avance o promoción de un punto de vista religioso según el cual un ser supranatural creó a la humanidad».

Es importante destacar que en en el caso Edwards la Corte apela a la «impresionabilidad de los menores» y a la coerción o incidencia que el avance de la religión por parte de las instituciones públicas puede producir sobre sus conciencias al afirmar que:

La Corte debe ser especialmente vigilante en el control de las prácticas que puedan vulnerar la Cláusula de Establecimiento en escuela primaria y secundaria. Las familias envían a sus hijos a la escuela pública con el propósito de que en ella no se avancen puntos de vista religiosos que podrían entrar en conflicto con las creencias privadas de los estudiantes y las de su familia.

403 U.S. 602 (1971). 
De manera que, según los postulados de la Corte, aquello que puede contradecir el derecho educativo paterno es la introducción en el currículo educativo de una materia que trate de avanzar una religión concreta. Así trazó una clara distinción entre la promocional «enseñanza de la religión» en el seno de la escuela pública — «teaching of religion»—, que se halla constitucionalmente prohibida, y la objetiva "enseñanza sobre la religión», que es constitucionalmente admisible — «teaching about religion»-

En el caso School District of Abington Township v. Schempp $(1963)^{8}$ se contienen las directrices básicas de la doctrina de la Corte Suprema norteamericana en relación con la enseñanza religiosa en las escuelas públicas: la Establishment Clause impide a estas instruir en el carácter falso o verdadero de las proposiciones religiosas, lo cual no obsta para que en ellas pueda formarse a los alumnos «sobre» la comprensión religiosa o, incluso, sobre los textos religiosos, pero siempre en el marco de un programa educativo secular. En este sentido, son significativas las palabras de la Corte cuando dispone:

Bien puede decirse que la educación de los menores no es completa si en ella no se incluye un estudio comparativo de las religiones y de su historia así como del papel trascendente jugado por las mismas en la evolución de las sociedades. El estudio de la Biblia, en consecuencia, debería introducirse como parte de los programas educativos seculares por su interés literario e histórico, pero siempre presentado desde una perspectiva de objetividad, en cuyo caso resultará compatible con la Primera Enmienda.

De ello se deduce que en los planes educativos de la escuela pública norteamericana solo cabe introducir la llamada «enseñanza sobre la religión» que, en palabras de la Corte, puede incluir «además del estudio de la Biblia por sus cualidades literarias e históricas, el estudio comparado de las diversas religiones, la historia de las mismas y la relación entre la religión y el avance de la civilización».

Siguiendo dicho razonamiento, la Corte Suprema ha reafirmado la distinción introducida en el caso Schempp en sus pronunciamientos posteriores al sostener, por ejemplo, en el caso Stone v. Graham $(1980)^{9}$ que las escuelas públicas pueden incluir en sus planes educativos el análisis de los diez mandamientos siempre y cuando se haga "en el marco de un apropiado estudio de la historia, de la civilización, de la ética y de la religión desde una perspectiva comparada». O cuando, en el caso Edwards v. Aguillard $(1987)^{10}$, mantiene que «instruir a los

\footnotetext{
374 U.S. 203 (1963).

449 U.S. 39 (1980).

482 U.S. 578 (1987).
} 
estudiantes en una pluralidad de teorías científicas sobre el origen de la humanidad es constitucionalmente admisible cuando tiene el claro y secular objetivo de incrementar la efectividad de la instrucción científica».

\section{LA OBJECIÓN A LA EDUCACIÓN FÍSICA Y A LA NATACIÓN}

La Sentencia de 10 de enero de 2017 plantea, como ha quedado expuesto, la negativa de unos padres musulmanes a que sus hijas menores de edad acudan a clases obligatorias mixtas de natación porque, según la interpretación que los mismos realizan de los preceptos de la religión musulmana, esta impide a las menores mostrar su cuerpo ante los demás alumnos.

Aun cuando hemos visto cómo existe una clara preeminencia jerárquica del derecho de los menores a recibir una educación integral identificado, prima facie, con el deber de seguir todas y cada una de las materias que integran la educación básica obligatoria siempre que estas cumplan una serie de requisitos de contenido y método de impartición, frente al derecho educativo paterno, no hay que olvidar que atender a las particularidades de cada caso concreto se hace imprescindible para evitar vulneraciones imputables a la desproporcionalidad en la restricción del derecho que cede en la ponderación.

$\mathrm{Y}$ esto fue puesto de manifiesto por el Tribunal Administrativo Federal alemán en sus dos pronunciamientos sobre objeciones paternas similares a la trazada en la sentencia de Estrasburgo objeto de estudio.

En sendas sentencias ${ }^{11}$, donde se planteaba el conflicto entre la obligación de acudir a las clases de gimnasia — como parte del deber de escolarizacióny la objeción esgrimida por dos niñas turcas de 12 y 13 años que profesaban la religión musulmana, el Tribunal falló a favor de la pretensión de las escolares y de sus padres, que trataban de obtener una dispensa en tanto en cuanto la Administración educativa no estuviera en condiciones de acomodar su demanda. La argumentación del Tribunal giró en torno a la importancia de los sentimientos religiosos de las recurrentes y al conflicto de conciencia que para ellas podía suponer desobedecer las prescripciones de su propia fe y ahondó en la idea de que la Administración educativa se hallaba obligada a buscar todas las vías posibles para evitar el conflicto.

Con dicho planteamiento no se trataba de reconocer un derecho subjetivo al establecimiento de una clase de educación física acorde con las prescripciones religiosas de quien reclama la exención o de reconocer una dispensa general para aquellos a los que la asistencia a dicha materia les genere un conflicto de conciencia, pero sí de atender a las máximas del «juicio de necesidad o

11 BverwGE 94, 82, de 25 de agosto. 
indispensabilidad», integrante del principio de proporcionalidad, con el fin de llegar a soluciones lo más acertadas posibles desde una perspectiva constitucional. Como se recordará, dicho principio rechaza la constitucionalidad de todas aquellas medidas que restringen un derecho fundamental —en orden a la satisfacción de otro derecho o bien constitucional - sin ser las menos gravosas. En tanto en cuanto el bien constitucional que alcanza superioridad jerárquica en este tipo de conflictos se identifica incuestionablemente con el derecho de la menor a cursar la asignatura de gimnasia, necesaria para su adecuado desarrollo, impedir una restricción desproporcionada de las convicciones paternas pasa por buscar soluciones flexibles como permitir la asistencia a la clase de educación física con una vestimenta distinta a la preceptiva prenda deportiva escolar en tanto en cuanto, con ello, no se estarían alterando los contenidos de la materia.

A este respecto, la Sentencia de 10 de enero de 2017 del Tribunal Europeo de Derechos Humanos es modélica, pues señala que las autoridades educativas suizas habían ofrecido a los demandantes distintas medidas reductoras del impacto que la asistencia a las clases de natación mixtas de las menores pudiese tener sobre las convicciones religiosas de sus padres. Así, existía la posibilidad de que las chicas asistiesen a las clases con un burkini, algo que los demandantes rechazaron por el efecto estigmatizador de la prenda y que la Corte consideró infundado, y que se cambiasen de ropa y se duchasen sin la presencia de alumnos del otro sexo.

\section{LA EDUCACIÓN «INTEGRAL» DE LOS MENORES}

La sentencia objeto del presente estudio reitera lo que ya viene a ser una doctrina bien acuñada por el Tribunal Europeo de Derechos Humanos, en virtud de la cual el derecho de los padres a adoptar la educación que consideren más adecuada para el menor, de conformidad con sus convicciones religiosas, ideológicas y filosóficas, debe entenderse, siempre y en todo caso, subordinado al derecho a la educación de aquel ${ }^{12}$. Pero ¿̨a qué tipo de educación se refiere el juez de Estrasburgo?

El primer rasgo que se deriva de la jurisprudencia europea es que esta ha de ser una educación no adoctrinadora, esto es, de carácter plural, neutral y objetivo. De esto se deduce que debe tratarse de una «educación democrática» que propicie la convivencia participada en libertad, respetuosa con las plurales opciones ideológicas, religiosas y filosóficas existentes en la sociedad y que forme ciudadanos activos, participativos y con capacidad crítica. Por lo que cabría

12 STEDH de 25 de febrero de 1982, en el caso Campbell y Cosans c. Gran Bretaña. 
afirmar que una educación sesgada, limitante, falseada en sus referentes científicos y contraria a los principios de convivencia y, por ende, a los valores del Convenio, no sería una educación «integral».

En este sentido, y teniendo en cuenta la ponderación de los intereses en juego, la Sentencia de 10 de enero del 2017 es significativa, pues en ella la Corte comparte el argumento del Gobierno suizo, en virtud del cual la escuela ocupa un lugar especial en el proceso de integración social, incluso más crucial en el caso de los niños extranjeros. Así, acepta que, dada la importancia de la educación obligatoria para el desarrollo del niño, la autorización de excepciones para la asistencia a ciertos cursos solo esté justificada en casos muy excepcionales, en condiciones definidas y de acuerdo con la igualdad de trato de todos los grupos religiosos. Además, afirma expresamente que el interés de los niños en recibir una educación completa que permita su integración social mediante las costumbres locales prima sobre el deseo de los padres de ver a sus hijas exentas de las clases de natación mixtas.

Pero especialmente significativo es el párrafo de la sentencia en el que el Tribunal Europeo atribuye un valor adicional a la asignatura de natación que va más allá de la importancia que la misma tiene para la salud física de los niños, apelando al carácter integrador de la actividad cuando esta es desarrollada en común entre todos los nińos de la clase. Así, afirma expresamente:

La enseñanza de los deportes como la natación es de singular importancia para el desarrollo y la salud de los niños. Sin embargo, el interés primordial de esta enseñanza no reside sólo en aprender a nadar y ejercer una actividad física, sino en el desarrollo de la misma en común con el resto de estudiantes, sin ningúna excepción basada en el origen de los niños o en las creencias religiosas o filosóficas de sus padres.

Por lo que respecta a la alegación de los demandantes de que sus hijas asisten a clases de natación privadas, la Corte reitera que no se trata de practicar una actividad física o aprender a nadar —objetivos en sí mismo legítimos-, sino de aprender juntos y practicar esta actividad en común.

Dicho valor socializador y de integración de la clase de natación reconocido por el Tribunal Europeo de Derechos Humanos nos recuerda a lo afirmado por el Tribunal Constitucional español en una importantísima sentencia del año 2010 en relación a un supuesto de homeschooling o enseñanza en casa (Martín Retortillo Baquer, 2013).

En aquella ocasión, un juez constitucional español afirmó que:

La educación a la que todos tienen derecho y cuya garantía corresponde a los poderes públicos como tarea propia no se contrae a un proceso de mera 
transmisión de conocimientos, sino que aspira a posibilitar el libre desarrollo de la personalidad y de las capacidades de los alumnos y comprende la formación de ciudadanos responsables llamados a participar en los procesos que se desarrollan en el marco de una sociedad plural en condiciones de igualdad y tolerancia, y con pleno respeto a los derechos y libertades fundamentales del resto de sus miembros. Y el mandato de su consecución es el principio constitucional al que sirve la imposición normativa del deber de escolarización en el marco de la enseñanza básica obligatoria (Martí Sánchez, 2011; Valero Heredia, 2012; Parody Navarro, 2011).

Se observa cómo ambos tribunales coinciden en afirmar con rotundidad que la educación y, por ende, la impartición y desarrollo de las materias que integran el currículo educativo obligatorio a través del cual esta se materializa no consiste en la mera transmisión de contenidos, sino que requiere, además, la formación en un conjunto de valores democráticos que favorezcan el libre desarrollo de la personalidad de los menores y su integración en una sociedad democrática como auténticos ciudadanos de la misma, pues solo de este modo se conseguirá su educación integral (Salguero Salguero, 1999; De Esteban y López Guerra, 1980).

En dicho sentido continúa la Sentencia 133/2010, de 2 de diciembre, del Tribunal Constitucional español:

La finalidad que deben perseguir los poderes públicos a la hora de configurar el sistema educativo en general y la enseñanza básica en particular ha de servir a la garantía del libre desarrollo de la personalidad individual en el marco de una sociedad democrática y a la formación de ciudadanos respetuosos con los principios democráticos de convivencia y con los derechos y libertades fundamentales, una finalidad ésta que se ve satisfecha más eficazmente mediante un modelo de enseñanza básica en el que el contacto con la sociedad plural y con los diversos y heterogéneos elementos que la integran, lejos de tener lugar de manera puramente ocasional y fragmentaria, forma parte de la experiencia cotidiana que facilita la escolarización -FJ 8-.

La educación es, entre otras cosas, el principal instrumento de socialización y una herramienta imprescindible para la convivencia democrática ${ }^{13}$. En

13 Con fecha 11 de febrero de 2009, el Tribunal Supremo español se pronunció en relación con los recursos de casación interpuestos por la junta de Andalucía, el Ministerio Fiscal y el abogado del Estado contra la sentencia del Tribunal Superior de Andalucía que reconocía a unos padres el derecho a objetar en conciencia para que sus 
este sentido, en tanto en cuanto la instrucción en valores democráticos requiere la puesta en práctica de un contexto educativo basado en los principios de apertura e integración social, que ofrezca a los alumnos una visión del mundo lo menos sesgada posible, la enseńanza en casa o en el seno de grupos fuertemente ideologizados, o apartar a los menores de determinadas materias curriculares cuando estas cumplen con los requisitos de objetividad, neutralidad y pluralismo señalados por el Tribunal Europeo de Derechos Humanos, solo puede ir en detrimento de su educación integral y, por ende, de su formación como individuos libres (Aláez Corral, 2011).

A la vista de todo lo expuesto debemos concluir que el Estado está llamado a desempeñar un rol fundamental en la garantía efectiva de una educación democrática de la ciudadanía. En este sentido, la escuela debe ser un ámbito de aprendizaje no solo de conocimientos, sino también de formación en los principios y valores de ciudadanía que la Constitución y el Convenio Europeo de Derechos Humanos establecen, y un ámbito de socialización en los mismos en orden a garantizar la educación integral del menor. Por ello el Estado no está obligado a adecuarse a las concepciones religiosas, ideológicas o filosóficas de los padres, pues la proyección en la escuela del derecho de estos a orientar la educación de sus hijos solo tiene un carácter negativo, que obliga al Estado a no incurrir en ningún tipo de adoctrinamiento.

\section{Bibliografía}

Aláez Corral, B. (2003). Minoría de edad y derechos fundamentales. Madrid: Tecnos.

- (2008). Caso Folgero y respeto a las convicciones morales de los padres en materia educativa. Revista Aranzadi del Tribunal Constitucional, 3, 13-29.

- (2011). El ideario educativo constitucional como límite a las libertades educativas. Revista Europea de Derechos Fundamentales, 17, 91-129.

Barrero Ortega, A. (2009). Tribunal Europeo de Derechos Humanos: TEDH Sentencias de 26.06.2007, Folguero y otros c. Noruega, 15472/02, y de 09.10.2007, Hasan Eylem Zeguín c. Turquía, 1448/04: Objeción de conciencia de los padres a la educación con implicaciones morales, enseñanza religiosa obligatoria. Revista de Derecho Comunitario Europeo, 32, 259-274.

hijos no asistiesen a clase de la asignatura Educación para la ciudadanía, incluida como obligatoria en el currículo educativo oficial por la Ley Orgánica 2/2006, de 3 de mayo, de Educación. El Tribunal Supremo estimó el recurso declarando que no es constitucionalmente admisible que el Estado no tenga nada que decir sobre la educación de los menores, ni que no quepa ninguna transmisión de valores a través del sistema educativo, por lo que el deber de cursar la citada materia es un deber jurídico válido y no cabe la objeción de conciencia al seguimiento de la misma. 
De Esteban, J. y López Guerra, L. (1980). El régimen constitucional español. Barcelona: Labor.

Martí Sánchez, J. M. (2007). Objeciones de conciencia y escuela. Revista General de Derecho Canónico y Derecho Eclesiástico del Estado, 15, 1-55.

- (2011). El «homeschooling» en el derecho español. Revista General de Derecho Canónico y Derecho Eclesiástico del Estado, 25, 1-40.

Martín Retortillo Báquer, L. (2013). Los derechos de los padres sobre la educación de sus hijos según la jurisprudencia del Tribunal Europeo de Derechos Humanos, y la «enseñanza en casa». Revista Española de Derecho Administrativo, 158, 157-186.

Parody Navarro, J. A. (2011). Sobre la práctica del «Homeschooling» en Espańa y la jurisprudencia europea. Revista Europea de Derechos Fundamentales, 17, 299-320.

Polo Sabau, J. R. (2003). Libertades educativas y aconfesionalidad en la Constitución de los Estados Unidos. Laicidad y Libertades: Escritos Jurídicos, 3, 347-384.

Salguero Salguero, M. (1999). La cultura de los derechos fundamentales como garantía de la democracia. Derechos y Libertades: Revista del Instituto de Derechos Humanos Bartolomé de las Casas, 7, 441-446.

Valero Heredia, A. (2009). La libertad de conciencia del menor de edad desde una perspectiva constitucional. Madrid: Centro de Estudios Políticos y Constitucionales.

(2012). Ideario educativo constitucional y Homeschooling: A propósito de la Sentencia del Tribunal Constitucional 133/2010, de 2 de diciembre. Revista Española de Derecho Constitucional, 94, 411-442. 